\title{
Introduction to Expert Opinions on appropriate use of databases in cardiothoracic research: Pounding nails with a screwdriver
}

\author{
Eugene H. Blackstone, MD
}

Lauer and Blackstone ${ }^{2}$ reviewed various types and purposes of databases in cardiology and cardiac surgery that are germane to the series of expert opinions in this issue of the Journal on the use of these databases for published research. ${ }^{1,3-5}$ No database contains all the information about clinical encounters. Rather, each type of database contains a different fraction of the information, with different granularity and specificity, on the longitudinal health care of individuals, and each is constructed for a different purpose, although they at times overlap. Each has specific strengths and limitations when used for answering research questions. I borrow much of the material below from that article and from Chapter 6 of the Kirklin/Barratt-Boyes text. ${ }^{6}$

\section{REGISTRY}

A registry is a database containing a few core data elements on every individual in a defined population. Originally, a registry was a physical place in which registers are kept, and the person keeping these was a registrar. Registries represent an ongoing activity that is typically narrow in content (number of variables) but all-encompassing of those requiring registration. They are most often official or governmental. Registries of this type that are of particular importance in medical research include national registries of vital statistics or of prevalence of diseases. However, registries in cardiothoracic surgery have incorporated hundreds and even thousands of variables not necessarily related to the original purpose of the registry. Therefore, they are not very registry-like in terms of having few variables, but they maintain the attribute of including consecutive series

\footnotetext{
From the Sydell and Arnold Miller Family Heart, Vascular, and Thoracic Institute, Cleveland Clinic, Cleveland, Ohio.

Disclosures: The author reported no conflicts of interest.

The Journal policy requires editors and reviewers to disclose conflicts of interest and to decline handling or reviewing manuscripts for which they may have a conflict of interest. The editors and reviewers of this article have no conflicts of interest.

Received for publication May 26, 2021; revisions received May 26, 2021; accepted for publication May 26, 2021; available ahead of print June 8, 2021.

Address for reprints: Eugene H. Blackstone, MD, Department of Thoracic and Cardiovascular Surgery, Cleveland Clinic, 9500 Euclid Ave/Desk JJ-40, Cleveland, OH 44195 (E-mail: blackse@ccf.org).

J Thorac Cardiovasc Surg 2021;162:1143-5

$0022-5223 / \$ 36.00$

Copyright (C) 2021 by The American Association for Thoracic Surgery

https://doi.org/10.1016/j.jtcvs.2021.05.042
}

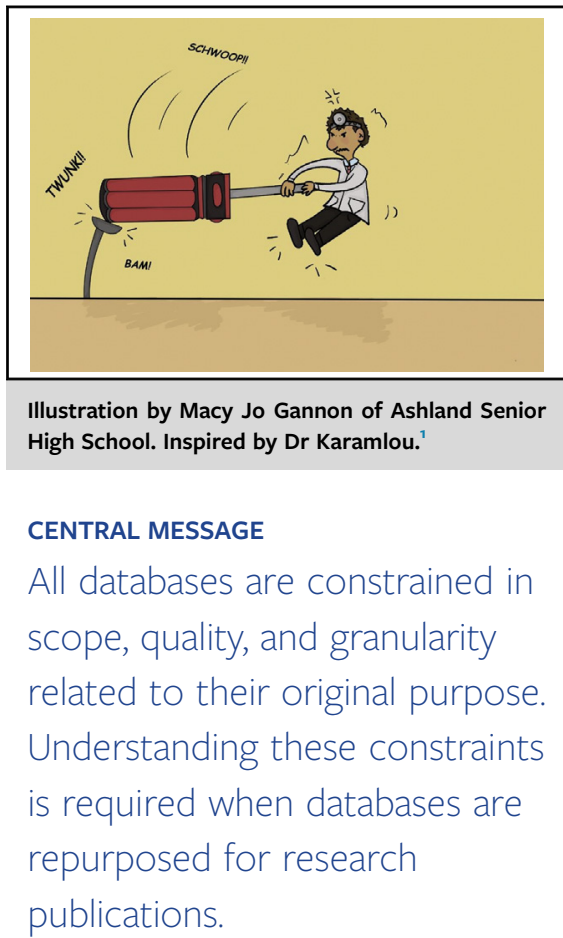

See Articles on pages 1146, 1157, 1166, and 1173

of all cardiothoracic operations on an ongoing basis, often at considerable expense to institutions. ${ }^{7}$

\section{RESEARCH DATABASE}

A research database consists of in-depth data about a defined set of patients meeting specific inclusion and exclusion criteria. In contrast to a registry, a research database encompasses a subgroup of patients relevant to answering or investigating a research question, is generally timelimited, not ongoing, and consists of granular data. Williams and McCrindle have called such a database an "academic database," because it usually is constructed by those in academic institutions to facilitate clinical research. ${ }^{8,9}$ Often such a database merges data that may be in a surgical registry, with data from other sources such as an echocardiographic registry, anesthesia registry, pulmonary function registry, follow-up registry, mortality registry, governmental neighborhood attribute, or census registries, for example. 


\section{ADMINISTRATIVE DATABASE}

An administrative database is usually a registry that consists of patient demographics, diagnostic (International Classification of Diseases, SNOMED) and procedural (Current Procedural Terminology) codes, and generally cost data, typically from billing systems. Granularity and accuracy of the data are generally limited to the specific purpose and specifications for which the database/registry is designed. Typically, these databases are maintained by hospital administration, with data abstracted from medical records by coders, and are part of "business intelligence." Generally, these coders are schooled in exacting definitions and use of administrative codes, and these may differ from medical definitions (is an "incision" by a surgeon an "iatrogenic laceration"?). Working directly with the billing department to understand the specific language they are looking for in doctors' notes, operative reports, and discharge notes pays dividends.

\section{NATIONAL DATABASE}

A national database-at least the derivative therefrom that can be used in research-consists of deidentified data containing meaningful medical variables, including patient demography, history, present condition, some laboratory and diagnostic data, procedure details, and adverse outcomes in addition to administrative codes. Generally, these too are registries. National (and international) databases are intended to be used for quality assessment; medical health quality improvement; government activities at a regional, national, or international level; and public consumption, such as those from the Centers for Medicare \& Medicaid Services, cancer registries, death registries, census bureau agencies, and so forth.

In one or another sense, the 4 expert opinions touch on all these database types, pointing out important strengths and inherent weaknesses for research. Karamlou and colleagues, ${ }^{1}$ with a whimsical screwdriver-and-nail analogy (Figure 1), ${ }^{10}$ "pound in" a message repeated by all: databases are created for a purpose, which constrains both their utility and their limitations. Particularly for administrative and national databases based on billing codes, a common theme is attempting to use these databases outside these constraints. Karamlou and colleagues ${ }^{1}$ carefully lay out the strengths and limitations of administrative data while classifying the Society of Thoracic Surgeons databases not as quality registries but as clinical research databases. This is countered by Kurlansky, ${ }^{4}$ who views these databases as having become "swollen," degrading data quality, and, from experience, introducing contradictory redundancy, incomplete fields, and ambiguous broken linkage between "parent and child" variables, and the like. All this comes at high institutional cost with low return on investment. Both Karamlou and colleagues and Kurlansky

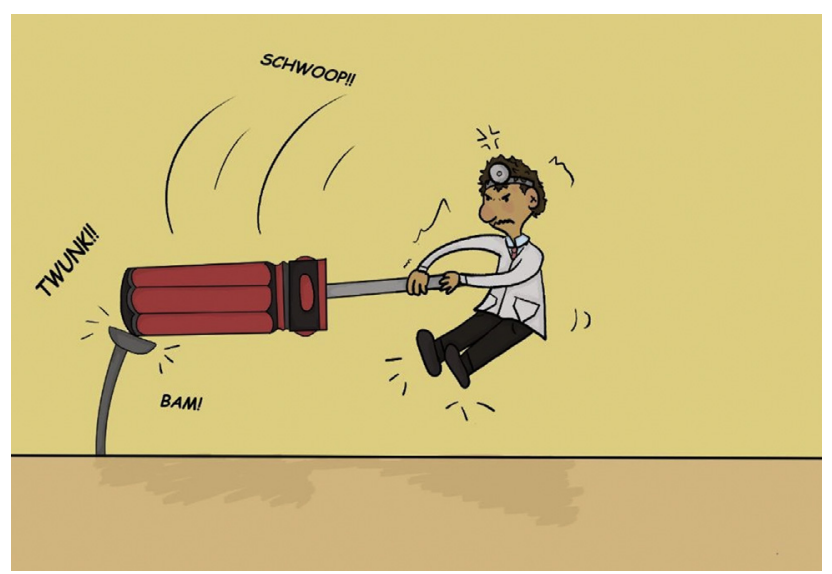

FIGURE 1. "Don't use a screwdriver to pound a nail. It takes forever and wrecks the screwdriver." Karamlou and colleagues ${ }^{1}$ cite this anonymous adaptation of Abraham Maslow's law of the instrument: "I suppose it is tempting, if the only tool you have is a hammer, to treat everything as if it were a nail." ${ }^{10}$ The universal message of the 4 expert opinions on appropriate use of databases for research, and particularly national registries, is that these registries were created for a specific purpose and, therefore, are constrained in scope. When they are repurposed for clinical research, it is important to understand these constraints, and to determine whether the registry selected is appropriate to answer the research question. Illustration by Macy Jo Gannon of Ashland Senior High School, Ashland, Ohio.

point to published guidelines for appropriate use of such databases.

Subramanian and colleagues ${ }^{5}$ provide important insights on the strengths and limitations of national databases whose primary purpose is health care reimbursement. Certainly, the economics of health care is a highly relevant field for research. An important aspect of the databases is that, to at least some extent, they provide a longitudinal picture of patients' health care encounters, something most hospital electronic health record systems lack.

I mention a few of the types of databases we encounter as a ploy to the purposeful, more limited perspective of Kidane and colleagues, ${ }^{3}$ who state that "databases are created to serve 1 of 2 fundamental functions: (1) research and (2) benchmarking quality." Certainly, these are 2 important types of databases, and the use of other types for either research or quality comes with considerable constraints. What Kidane and colleagues ${ }^{3}$ do very well and distinct from the other expert opinions is to explicitly spell out the strengths and limitations (boundaries, constraints) of databases most frequently encountered in this Journal, particularly in the field of general thoracic surgery. These describe both North American and European major databases. If one works within the strengths of these databases and does not use them for purposes for which they are ill-suited, they provide useful data for a considerable range of research.

What only Kurlansky ${ }^{4}$ does, almost as a footnote, is discuss the strengths and limitations of individual institutional research databases. These provide an opportunity 
for in-depth investigation not attainable in any of the databases discussed-down to the genome, proteome, microbiome, and all the other -omes. They suffer from referral and patient selection patterns that limit generalizability, small numbers that limit comparisons, confounding by skill level, and unmeasured or unaccounted for institutional and geographic factors. However, within those constraints, there is much that can be learned, so long as the constraints of these data are not violated and made transparent.

\section{References}

1. Karamlou T, Javorski MJ, Weiss A, Pasquali SK, Welke KF. Utility of administrative and clinical data for cardiac surgery research: a case-based approach to guide choice. J Thorac Cardiovasc Surg. 2021;162:1157-65.

2. Lauer MS, Blackstone EH. Databases in cardiology. In: Topol EJ, ed. Textbook of Cardiovascular Medicine. 2nd ed. Philadelphia: Lippincott Williams \& Wilkins; 2002:981-1103.

3. Kidane B, Wakeam E, Meguid RA, Odell DD, for the Thoracic Surgery Outcomes Research Network (ThORN) Inc. Administrative and clinical databases: general thoracic surgery perspective on approaches and pitfalls. J Thorac Cardiovasc Surg. 2021;162:1146-53.

4. Kurlansky P. The rocky exhilarating journey from data to wisdom. J Thorac Cardiovasc Surg. 2021;162:1166-9.

5. Subramanian MP, Hu Y, Puri V, Kozower BD. Administrative versus clinical databases. J Thorac Cardiovasc Surg. 2021;162:1173-6.

6. Kouchoukos NT, Blackstone EH, Hanley FL, Kirklin JK. Kirklin/Barratt-Boyes Cardiac Surgery: Morphology, Diagnostic Criteria, Natural History, Techniques, Results, and Indications. 4th ed. Philadelphia, PA: Elsevier/Saunders; 2013 253-352.

7. Blackstone EH, Swain J, McCardle K, Adams DH, Governance Committee, American Association for Thoracic Surgery Quality Assessment Program. A comprehensive American Association for Thoracic Surgery quality program for the 21st century. J Thorac Cardiovasc Surg. 2019 158:1120-6.

8. Williams WG, McCrindle BW. Practical experience with databases for congenital heart disease: a registry versus an academic database. Semin Thorac Cardiovasc Surg Pediatr Card Surg Annu. 2002;5:132.

9. Williams WG. Uses and limitations of registry and academic databases. Semin Thorac Cardiovasc Surg Pediatr Card Surg Annu. 2010;13:66-70.

10. Maslow AH. The Psychology of Science: A Reconnaissance. New York: Harper \& Row; 1966:15. 